\title{
Know Thyself: Jane Discovers the Value of Her Depression
}

\author{
Tamara Kayali Browne
}

\subsection{Introduction}

Western culture tends to view depression more often than not as something to be avoided and eradicated. (Of course, Western culture is not the only one that views depression in this way, but it is worth remembering that there are other cultures that view it differently. For example, Kleinman [1] notes that dramatic expressions of grief and depression are valued in the Kaluli society of Papua New Guinea. In Shiite Muslim Iranian culture, depression is associated with "living justly in an unjust world" and as such, part of a religious experience. Buddhists consider pleasureseeking as the source of suffering. For them, the state of pleasure-denial, which could be construed as mild depression, is the path to enlightenment. The term "Western culture" in this chapter functions only as a loose term to distinguish itself from other cultures such as these that value depression very differently.) Yet there are individuals who have been through the journey of depression, diagnosis and treatment who challenge this view. Another cultural value-gaining insight and self-discovery - can actually arise from the journey into and out of depression.

Jane's story that follows elucidates such a journey and what can be gained from examining the path that led one towards depression. The story is taken from my qualitative study of 37 women in the UK who were diagnosed with and treated for depression (see Guide to Further Sources). The study examined issues of the self in depression, asking participants for their views on, for example, whether depression/ its treatment challenged their sense of authenticity or their views of their future with depression.

T. K. Browne $(\square)$

School of Medicine, Deakin University, Geelong, VIC, Australia

(C) The Author(s) 2021

D. Stoyanov et al. (eds.), International Perspectives in Values-Based Mental

Health Practice, https://doi.org/10.1007/978-3-030-47852-0_37 


\subsection{Case Narrative: Jane's Story}

Jane (not her real name) is a white, middle-class woman who works as a children's social worker. She has a husband and children and was first diagnosed with depression when she was a university student aged about 17, and suffered from it for most of her degree. The event that sparked this first episode of depression was the breakup of a serious romantic relationship - a break-up that left her suicidal. She sought medical help but felt that the support of her friends and seeking solace in religion were the most important factors in helping her out of that first episode.

Since then, she has suffered from bouts of depression throughout her life and has been treated with both medication and talking therapy. The talking therapy prompted her to examine how her early childhood contributed to her sense of self. Her mother left her when she was 1 year old and her father left when she was five. She was then raised by her aunt and her grandparents. She met her mother in her thirties but after a couple of years her mother did not wish to remain in contact.

She describes herself as having been a nervous and withdrawn child, but did not realize the full impact that her childhood traumas and losses had on her until she began talking therapy. As she describes:

[...] looking back, a lot of it has got to do with attachment and loss and the denigration of not being worth anything comes to the fact of that early period I would say [...]

Me: So how does it help to know why it's happened?

I think because before a lot of the reasons I'd put defenses up were to protect myselffrom other people getting near me in case the same thing happened again. So understanding why they are there and what has happened enables me to bit by bit break that down because there is a reason for it.

Through her talking therapy, Jane came to understand herself better-something which she believes has been crucial to helping her understand her depression. By learning the reasons behind it, she felt armed with the ability to overcome it.

This is not to say that she does not believe biological factors played any role in her depression. She pondered whether the events that happened to her initiated certain neural pathways, or whether the neural pathways preceded her life events. She thinks her mother may have suffered from depression and therefore wonders whether there is an element of inheritance in her depression. However, she also states, "What I am certain about is because of what has happened in my life I have ended up being depressed."

When I asked Jane in which state she feels authentic, she was unsure, but said that she hopes it is the therapy that has contributed to her authentic self and not the medication. Her reason for this is apparent in the way she speaks about therapy:

I would hope that it is the therapy that has made me the real me and given me my confidence and self-esteem and self-worth and all of that. I don't think tablets can do that for you. They can enable you to switch off so that you're not so concerned about things but they can't enable... Well I don't think they can, and they certainly haven't in my case - enabled me to build up those parts of my life, parts of me that I denigrate all the time. 
Me: So if you had to choose one particular form of help, what would you pick?

I would pick therapy. I would pick therapy [...] I think you can use medication to kind of take you out of [a depressive state] a bit so you can cope with the therapy. But I think long-term I think it has to be therapy.

\section{Finally, I asked:}

If, in theory, there was a button that you could press that would get rid of depression from your life forever, would you press it?

That is a big question. I suppose in one sense I'd have to say yes because it's not a very pleasant thing to go through and I wouldn't like to see anybody else go through it, particularly my family. In another sense I would have to say it's taught me an awful lot about myself, and I think part of that is because of the therapy that I've had. If I'd have just been on medication I think my answer to that would have just been yeah. But having had the therapy, I think I've learnt an awful lot about myself. I'm much more self-aware and certainly with some of the children that I work with at school, can see things in a different kind of light with greater understanding and respect and empathy. So for that reason I would say no $[\ldots]$

\subsection{Values Arising}

Jane's story demonstrates the value of examining the individual's life context, as this proved key for Jane in helping her to understand her depression and, as a result, the tools to be able to overcome it. It was learning the meaning and significance of her past and the context in which her depression arose that was crucial to her improvement. She is careful not to negate the possible role that one's biology might play in depression's aetiology, but whether she had biological factors which predisposed her to depression that was triggered by life events, or whether it was the life events which set in motion certain biological processes, she is not sure. However, she is certain that the life events she experienced were key factors in her depression. Without understanding her own life, she could not overcome depression. In this way, Jane demonstrates the values that society places on gaining insight in order to better understand oneself.

It is also apparent from Jane's story that she does not simply value mental wellbeing, or mental well-being by any means, but achieving it via learning and insight. This is emphasised by the fact that the insight she gained from therapy was so valuable that she would not choose to be rid of depression forever with the press of a button, despite the suffering involved, due to the opportunity it provides to learn about oneself. While medication, she feels, has its role, it cannot replace the role of therapy, which she sees as helping one understand oneself and the reasons behind one's depression. Jane's story thus also demonstrates two values that can sometimes be seen to be in opposition - the value placed on seeking medical help and taking medication, but also the value in eventually being free of medication. 


\subsection{The Influences of Culture}

The value that Jane places on self-growth through knowledge and insight is reflected in the value placed on it in Western culture. Here, I draw on Ryff's definition of self-growth, which is to "develop one's potential, to grow and expand as a person" ([2], p. 1071). It is not that other cultures do not also value self-growth, but this definition of self-growth has its roots in both the Enlightenment and the Romantic tradition [3]. For instance, the idea that the self could be shaped in whatever direction one desires was popular during the Enlightenment [4, 5]. In addition, the idea that the self must battle against external forces in order to express itself comes from the Romantics [3], as is the view of commitments "from marriage and work to political and religious involvement - as enhancements of the sense of individual well-being rather than as moral imperatives" ([6], p. 47). We can see this nuance reflected in Jane's story, in which she struggled against the influences of her childhood, and drew on religion, work and therapy to enhance her self-growth and well-being. Yet this self-growth, which in Jane's case can only be achieved by examining the context of her depression, contrasts with the widespread culture within biological psychiatry that currently focuses on symptoms rather than their context. Jane's story shows what we may potentially lose with such a focus. In Jane's story, the value placed on gaining insight in broader Western culture won out over an aspect of Western biological psychiatric culture, but this is not the case with everyone.

This clash of "a culture within a culture" of sorts manifests itself in other aspects of Jane's story. Western culture values science and medicine, and the status and legitimacy of the medical profession grant a similar level of legitimacy to the medical approach to depression. However, Western culture also values independence and self-efficacy, as well as "the natural"-all of which can be challenged when one feels dependent on medication (something "unnatural" which one ingests) to achieve or maintain mental well-being. These two values can sometimes be in opposition, as the status given to the medical approach may cause the individual to feel that they must remain on medication for depression indefinitely (especially if this is what their doctor advises) yet there is simultaneously a pull in the other direction coming from a society which also values the ability to function independently of what can be viewed as a chemical "crutch."

Finally, the way depression is often portrayed in society-as something uncontrovertibly negative that one should be rid of - contrasts with the view of some such as Jane who do not view it in such black and white terms. Despite their suffering, they also found value in their journey through depression and recovery. By understanding how and why they became depressed, they could make sense of why they are the way they are. In turn, this insight enabled a self-growth that they felt could not have been achieved through medication alone, or without having been depressed (as this had prompted the need for therapy in the first place). Jane's story thus shows how understanding the context of the individual's depression, rather than relying on symptomatology alone, can be crucial for their recovery. 


\subsection{Conclusions}

Jane's story exemplifies a number of values which manifest in Western culturesome of which are in tension and others not. Depression tends to be portrayed in straightforwardly negative terms - as an illness to be banished. Further, the focus of medical texts such as the Diagnostic and Statistical Manual of Mental Disorders is on symptomatology. In contrast, Jane's portrayal of depression is not as black and white. Although it is, in her words, "not a very pleasant thing to go through," the insights she gained from talking therapy were crucial to her self-growth. However, she would not have gained them had she not experienced depression, or had she taken medication alone. Self-growth through insight is also valued by society, but Jane recounts that this would not have been possible for her without understanding her past and how it led her to where she is. It is a testament to the value that can be gained from the journey through depression and recovery if one looks beyond the manifestation and alleviation of the individual's symptoms to the context in which their depression arose.

Acknowledgements Sincere thanks to all the participants who so generously gave their time to share their experiences for the study from which this case is drawn. Thank you to Dr. Furhan Iqbal for not only assisting with recruitment of participants for the study, but also for providing invaluable support and insightful debate. Thanks also to the Arnold Gerstenberg fund for their financial support for the study.

\subsection{Guide to Further Sources}

The case presented in this chapter is drawn from unpublished interview material from a study I conducted at the University of Cambridge. Further findings from this study have also been published as a book and two papers:

- Browne TK. Depression and the self: meaning, control and authenticity. Cambridge: Cambridge University Press; 2018 (http://www.cambridge. org/9781316503478).

- Kayali T, Iqbal F. Making sense of melancholy: sub-categorisation and the perceived risk of future depression. Health, Risk \& Society. 2012;14(2):171-89.

- Kayali T, Iqbal F. Depression as unhomelike being-in-the-world? Phenomenology's challenge to our understanding of illness. Medicine, Health Care and Philosophy. 2013;16(1):31-9.

\section{References}

1. Kleinman A, Good B. Introduction to culture and depression. In: LeVine RA, editor. Psychological anthropology: a reader on self in culture. Chichester: Wiley-Blackwell; 2010. p. 112-8. 
2. Ryff CD. Happiness is everything, or is it? Explorations on the meaning of psychological wellbeing. J Pers Soc Psychol. 1989;57(6):1069-81.

3. Christopher JC. Situating psychological well-being: exploring the cultural roots of its theory and research. J Couns Dev. 1999;77:141-52.

4. Taylor C. The moral topography of the self. In: Messer SB, Saas LS, Woolfolk RL, editors. Hermeneutics and psychological theory: interpretive perspectives on personality, psychotherapy, and psychopathology. Rutgers symposia on applied psychology, vol. 2. Piscataway, NJ: Rutgers University Press; 1988. p. 298-320.

5. Taylor C. Sources of the self: the making of the modern identity. Cambridge: Cambridge University Press; 1989.

6. Bellah RN, Madsen R, Sullivan WM, Swidler A, Tipton SM. Habit of the heart: individualism and commitment in American life. New York, San Francisco: Harper \& Row; 1985.

Open Access This chapter is licensed under the terms of the Creative Commons Attribution 4.0 International License (http://creativecommons.org/licenses/by/4.0/), which permits use, sharing, adaptation, distribution and reproduction in any medium or format, as long as you give appropriate credit to the original author(s) and the source, provide a link to the Creative Commons license and indicate if changes were made.

The images or other third party material in this chapter are included in the chapter's Creative Commons license, unless indicated otherwise in a credit line to the material. If material is not included in the chapter's Creative Commons license and your intended use is not permitted by statutory regulation or exceeds the permitted use, you will need to obtain permission directly from the copyright holder.

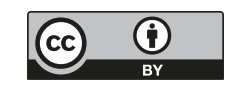

